\title{
De las luchas por el nemagón al asesinato de Jairo Mora: Reflexiones sobre cultura de protesta
}

Recibido: 13 de marzo 2018 Revisado: 12 de junio 2018 Aprobado: 10 de julio 2018

Sindy Mora Solano Socióloga costarricense.

Máster en Derechos Humanos y Educación para

la Paz. Investigadora del Instituto de Investigaciones Sociales (IIS), Universidad de Costa Rica (UCR).

Correo electrónico: sindy.mora@ucr.ac.cr
Resumen: En este artículo se presenta una reflexión en torno a la cultura de protesta costarricense, a partir del análisis de las manifestaciones realizadas por la población afectada por el DBCP, agroquímico conocido como nemagón, y por el asesinato del ambientalista Jairo Mora Sandoval en 2013. En el artículo se analiza la cultura de protesta y se discute si esta puede promover la impunidad.

Palabras clave: Protesta social; justicia; impunidad; agroquímicos; Jairo Mora Sandoval

\section{From the Struggles for the Nemagon to the Murder of Jairo Mora Sandoval: Reflections on Culture of Protest}

Abstract: This paper shows a discussion about Costa Rican culture of protest, on a basis of a case study of manifestations carried out by workers affected by DBCP, pesticide known as Nemagon, and protests helded in memory of Jairo Mora Sandoval, environmentalist who was murdered in 2013. This paper draws a discussion about how culture of protest might promote impunity.

Key words: Social protest; justice; impunity; pesticides; Jairo Mora Sandoval

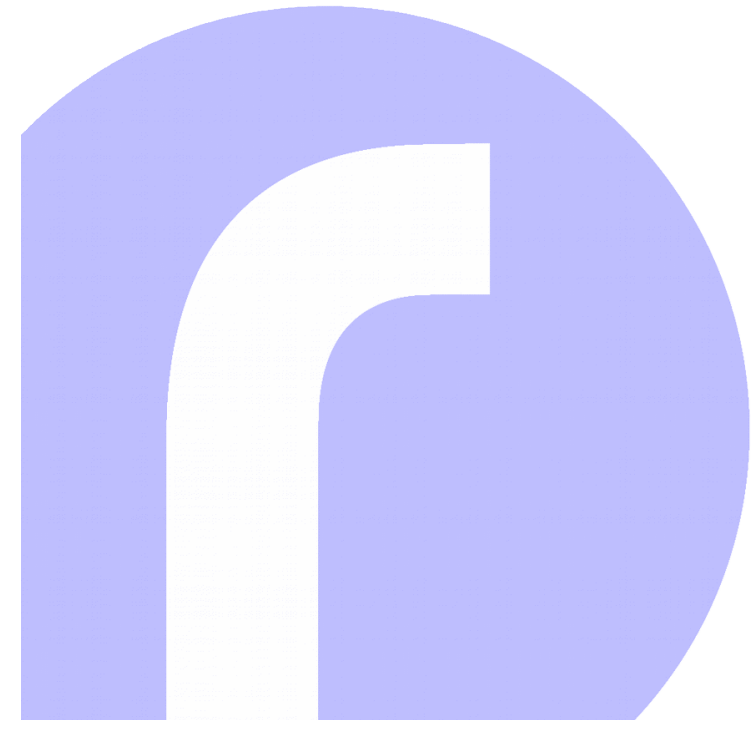




\section{Introducción}

Este artículo tiene por objetivo plantear algunos interrogantes sobre la cultura de protesta, tomando en consideración los espacios y las discusiones que tal mecanismo político aporta a las disputas que atraviesan al país. El análisis toma como punto de partida las manifestaciones de la población trabajadora bananera afectada por la exposición al DiBromoCloroPropano (DBCP), agroquímico conocido con el nombre comercial de nemagón, así como las protestas en búsqueda de justicia por el asesinato del ambientalista Jairo Mora Sandoval. Se han elegido estos casos pues es posible trazar un hilo común que va desde la extracción de recursos de una región históricamente empobrecida, la contaminación, la producción de enfermedades en la población, la represión política y la muerte hasta las dificultades para imponer sanciones a los responsables privados de dichas actuaciones. De la misma manera, ambos casos posicionan la conflictividad de la región Caribe en el espacio urbano del Valle Central.

La afectación por el uso y la exposición al nemagón ocurrió entre los años sesenta y setenta del siglo pasado, en zonas dedicadas al cultivo del banano ubicadas, fundamentalmente, en la región Caribe del país (Giralt 1996; Bohme 2012). La exposición a esta sustancia causó enfermedad y transformaciones en las relaciones familiares y sociales de la población expuesta. Por su parte, el asesinato de Jairo Mora Sandoval ocurrió en el 2013, luego de su su participación en la protección y conservación de las tortugas baula, en Moín, en la misma región. En ambos casos, es posible dar cuenta del poder empresarial presente en este espacio: la exposición y el uso del nemagón fue posible gracias a la producción, distribución e incorporación del agroquímico al proceso productivo del banano; por su parte, el asesinato de Jairo Mora Sandoval sucedió en un contexto de disputas territoriales, ante la construcción de la Terminal de Contenedores de Moín (TCM), concesionada a la empresa APM Terminals.

Si bien en ambos casos ha habido distintas expresiones de lucha en la zona, lo cual es importante subrayar en el marco de esta reflexión, significativas protestas dirigidas a una institucionalidad Estado-céntrica se han registrado en el Valle Central del país. Sobre este tema, es importante señalar que distintas investigaciones han apuntado a que un rasgo característico de la protesta social costarricense es que se encuentra dirigida, fundamentalmente, hacia el Gobierno y sus distintas instancias, lo que evidencia la legitimidad estatal en la resolución de los conflictos.

De esta manera, en una reconstrucción de diez años de acciones colectivas de protesta, Mora evidenció que estas formas de participación política se encontraban dirigidas, mayoritariamente, hacia las diversas instituciones gubernamentales (Mora 2008). Esa tendencia se mantiene hasta la actualidad en todos los temas, incluso el ambiental, como lo muestra el último Informe del

Estado de la Nación en Desarrollo Humano Sostenible del Programa Estado 
de la Nación (PEN, 2017). Así, al desarrollarse en el espacio vallecentralino, dichas manifestaciones han recibido más cobertura mediática, lo que no necesariamente significa que se haya logrado posicionar una discusión en torno a los poderes que se encuentran detrás de las extracciones, los procesos de contaminación, las enfermedades y las muertes producidas en la región. Por ello, en este texto se parte de la necesidad de discutir en torno a la cultura política de la protesta y sus implicaciones para la atención de las demandas.

Las manifestaciones a las que se hace referencia en este artículo se analizan a partir de la técnica de observación participante; se presenta una serie de fotografías tomadas por la autora en la fecha indicada. De la misma manera, se realiza una reconstrucción a partir de fuentes escritas, como reportajes periodísticos y pronunciamientos de las organizaciones participantes. Este trabajo se compone de los siguientes apartados. En el primero, titulado ¿Cómo y a quién le habla la protesta social?, se discuten algunas nociones de carácter teórico-conceptual y también se plantean algunas preguntas en torno a la cultura de la protesta en Costa Rica. En el segundo apartado, titulado Del Caribe a San José: encuentros en la calle, se presenta una reflexión sobre lo que implican o significan estas acciones colectivas de protesta. El artículo concluye con algunas reflexiones sobre el tema.

\section{¿Cómo y a quién le habla la protesta social?}

Como señala Javier Auyero, la protesta social tiene como objetivo fundamental visibilizar una demanda (Auyero 2002). Tal posicionamiento puede dirigirse hacia la institucionalidad ante la que se plantea una determinada reivindicación; a otras organizaciones nacionales o internacionales para la consecución de apoyo y el establecimiento de alianzas; o a medios de comunicación, con la finalidad de ampliar la cobertura y el reconocimiento. Sin embargo, una protesta no puede analizarse única y exclusivamente a partir del planteamiento de sus peticiones. La cultura de la protesta, los lugares sociales donde esta se realiza y las formas en las que se expresan las reivindicaciones frente a un actor político determinado son aspectos fundamentales para entender sus alcances y limitaciones.

Los repertorios de protesta social, es decir, las expresiones y prácticas vinculadas a la acción de protestar, se configuran a partir de factores de carácter cultural. Así, "el concepto de repertorio ubica a la cultura en el centro de las formas de acción colectiva al hacer foco en los hábitos de beligerancia adoptados por los distintos actores y en las formas que toma la acción colectiva como resultado de expectativas compartidas e improvisaciones aprendidas" (Auyero 2002, 18-19). En esa misma línea, Álvarez, Dagnino y Escobar han señalado la importancia de mirar en los movimientos sociales los procesos de significación y resignificación cultural de las nociones fundamentales de la vida política, dado que los movimientos son centrales no solo en el 
planteamiento de reivindicaciones o derechos particulares, sino en los procesos de producción cultural (Álvarez, Dagnino, y Escobar 1998).

Asimismo, la construcción sociopolítica de ciertos espacios como lugares de protesta, la utilización de determinada indumentaria, adornar el cuerpo con símbolos específicos, la escogencia de determinado lenguaje, la recurrencia a consignas o a tradiciones musicales particulares y la producción de determinados sentidos culturales forman parte de un repertorio cultural de la protesta social. Entonces, una marcha de sindicatos da cuenta de una estética, un lenguaje y una música diferentes a los de una marcha convocada por actores ambientalistas, colectivas feministas o actores conservadores, por poner un ejemplo.

Por ello, el establecimiento de ciertos espacios como lugares de protesta puede entenderse como resultado de la costumbre o la tradición cultural; y no necesariamente de la identificación o el reconocimiento de aquellos espacios donde se encuentran los poderes que efectivamente podrían atender y resolver una determinada demanda. Incluso, los distintos actores políticos involucrados en una protesta pueden apropiarse de maneras diferenciadas de los espacios sociales, en los que el género puede orientar las formas y los mecanismos en los que se utiliza el espacio de la protesta (Cohen y Frazier 2004).

En este sentido, y como se indicaba anteriormente, en Costa Rica, el Estado y su institucionalidad han sido identificados como las principales entidades frente a las que se plantean demandas específicas (Mora 2008; PEN, 2017). No obstante, es preciso señalar que no siempre se protesta frente al mismo Estado: este puede ser un Estado paternalista, un Estado garante de derechos, un Estado regulador o propiciador de conflictos o un Estado entendido como lugar de apertura política (Mora 2011); por lo tanto, es fundamental indagar frente a qué tipo de Estado nos estamos enfrentando cuando se trata de la protesta social.

En el marco de la cultura de la protesta, es fundamental preguntarse: ¿qué sucede cuando las violaciones de derechos y los procesos de desigualdad son producidos por actores de carácter privado?, ¿cuál es el curso que sigue la protesta en estos casos? y ¿a qué espacios es posible llevar la protesta en situaciones de este tipo? Como señala la literatura consultada, se trata de un tema sobre el que existe un abordaje limitado, tanto desde la perspectiva de los instrumentos jurídicos internacionales que sancionen la labor de las empresas privadas por las consecuencias de sus actos, ya sean nacionales o transnacionales, como desde la práctica política de los movimientos sociales (Galvis 2011; Slack 2011).

A nivel latinoamericano, uno de los casos que ha desatado más polémica ha sido el de la industria minera de capital canadiense en la región, lo que ha evidenciado las dificultades, cuando no la imposibilidad, de juzgar a estas empresas en Canadá y en los países donde se realizan las actividades mineras (Lebuis 2011). Otro evento que ha suscitado una enorme discusión ha sido el de las comunidades ecuatorianas del Amazonas contra la empresa Chevron, anteriormente Texaco, por la contaminación de ríos y fuentes de 
agua con 18500 galones de residuos tóxicos (Jochnick 2011). También ha sido significativo el movimiento de los trabajadores bananeros afectados por el nemagón en Nicaragua, en su esfuerzo por juzgar a las empresas bananeras estadounidenses que causaron enfermedades como la esterilidad masculina; esa experiencia transitó un amplio camino de dificultades $y$, posteriormente, culminó con la imposibilidad de sancionar a estas empresas, a partir de los juicios realizados en el territorio nicaragüense (Gómez 2013).

En el caso costarricense, ha sido posible identificar el surgimiento de organizaciones, frentes de lucha y movimientos que buscan sancionar la actuación de las empresas privadas; ya sea en el ámbito del sector turístico en la provincia de Guanacaste, con la realización de acciones de protesta espontáneas y no necesariamente sostenidas a lo largo del tiempo (Navarro 2013); así también, se han gestado acciones concretas en el ámbito local que limitan los permisos ante el avance de los proyectos mineros en el país, a pesar de las instancias gubernamentales que avalan tales licencias (Isla, 2002).

Los estudios mencionados evidencian lo que Jochnick ha denominado la impunidad empresarial, proceso mediante el cual las empresas causan daños a los cuerpos, a los colectivos y al ambiente; sin embargo, posteriormente, su proceder no es sancionado de ninguna manera (Jochnick 2011). Por el contrario, como parte de este fenómeno, las organizaciones sociales se enfrentan a una serie de dificultades como la ausencia de recursos y la falta de inspección por parte de las entidades gubernamentales, la corrupción existente en los Gobiernos y el acceso limitado a la justicia. Sobresalen todos estos elementos cuando los procesos judiciales concluyen con la absolutoria a este tipo de actores.

A pesar de los procesos que instituyen la impunidad empresarial, y justamente por ellos, la apropiación pública del espacio mediante las distintas expresiones de un repertorio de protesta puede ser examinada con el fin de comprender los alcances del posicionamiento de una determinada demanda. En ese sentido, es importante "entender la acción política no sólo como una lucha en el espacio, sino también como una lucha por y con el espacio, una lucha por la reapropiación de las capacidades, destrezas y capitales sociales para organizarlo" (Sevilla 2014, 210).

Por consiguiente, la indignación política no puede posicionarse en un lugar elegido azarosa o arbitrariamente; o sea, se deben desarrollar las habilidades para que ese espacio sea resignificado y permita el establecimiento de la denuncia, el intercambio político y la atención de las demandas. Así pues, uno de los retos consiste en posicionar manifestaciones que impugnen el proceder de actores privados en el proceso de producción de condiciones de injusticia y de desigualdad.

Es claro que la apropiación pública del espacio también permite una labor significativa en la articulación interna de las organizaciones, mediante "la conversión individual del dolor en duelo público" (Maihold 2012, 190). En esos espacios, el dolor compartido encuentra la reconstrucción colectiva necesaria que combate el olvido; y si no fuera por los mecanismos de la protes- 
ta social, entonces la impugnación de las condiciones que causan situaciones de injusticia y desigualdad sería una acción imposible. Precisamente, en este proceso de impugnación de un orden social desigual y excluyente radica el aporte de la protesta a los procesos de reconstrucción de las memorias por las disputas políticas.

No obstante, es pertinente agregar que el posicionamiento en el espacio público de una determinada demanda no es suficiente para que una reivindicación sea escuchada y mucho menos atendida. Ante este panorama, es necesario reflexionar en torno a cuáles son los mecanismos y los lugares en los que la protesta se posiciona para plantear reivindicaciones, lo que permitiría debatir si algunos de los aspectos culturales de la protesta social pueden comprenderse como un límite u obstáculo para el posicionamiento de las demandas. Seguidamente, se plantean algunas ideas en torno a los elementos culturales de la protesta en el país.

\section{Elementos culturales de la protesta en Costa Rica}

1. Un ejemplo de lo anterior son las protestas que se dirigen a la institucionalidad pública, a fin de que las empresas privadas realicen determinadas acciones, como el cumplimiento de sus obligaciones, lo que se ilustra con las protestas de 2012 ante la llamada "crisis" de la Caja Costarricense de Seguro Social (CCSS). En estas manifestaciones, las demandas se articularon en torno a la solicitud de que la Caja cobre lo adeudado a las empresas morosas con la seguridad social, pero no necesariamente se identifica a las empresas responsables de esta morosidad, como si fuese difícil trascender el ámbito de lo público y plantear estas demandas concretas, de manera colectiva, frente a entidades de carácter privado (Mora 2015)
En Costa Rica predominan, aunque no son exclusivas, las acciones de protesta dirigidas a la institucionalidad pública (Mora, 2008; PEN, 2017). Por ende, durante los últimos años, han sido comunes tales manifestaciones frente a la Asamblea Legislativa, en la provincia de San José, o que culminan frente a dicha institución después de una marcha dirigida hacia este lugar, a pesar de que la entidad a la que se dirige la acción puede ser el Gobierno central u otra institución pública.

En este sentido, la Avenida Segunda, en el centro de San José, y Cuesta de Moras, calle frente a la que se encuentra la entrada principal de la Asamblea Legislativa, se han convertido en espacios fundamentales del repertorio de protesta, donde se expresan discursos y se llevan a cabo actos culturales, a pesar de que, en ocasiones, el Parlamento costarricense podría no ser la entidad que motivó la movilización. Incluso, en el repertorio de la protesta nacional es común observar el desplazamiento de colectivos desde zonas rurales hacia el centro del país, con una gran inversión de una serie de recursos, tanto económicos como políticos, lo que no necesariamente lleva a que estos actores sean atendidos por los funcionarios de la institucionalidad frente a la que se protesta.

Por otro lado, pocas veces se establece con claridad una relación que interpele a la empresa privada, excepto cuando esta se encuentra detrás de las situaciones que movilizan a los actores colectivos; entonces, generalmente, la acción de protesta desarrollada es una huelga de trabajadores privados contra sus patronos. Esta excepción se debe a la centralidad de la institucionalidad pública en el posicionamiento de demandas políticas, lo que impide que se articulen acciones que trasciendan el mundo de lo público e imposibilita que la conflictividad se posicione en el ámbito privado. ${ }^{1}$ 
En este mismo sentido, tal dificultad se expresa en la imposibilidad de reconocer que los funcionarios públicos tienen una vida privada y habitan en un espacio determinado en el que se podría realizar una protesta, a diferencia de lo que sucede en otros países latinoamericanos. ${ }^{2}$

Otro de los rasgos culturales de la protesta social se relaciona con los horarios, los días y el efecto del clima en la protesta. Por lo general, las protestas que se realizan desde organizaciones de carácter sindical se convocan en horas de la mañana, de 9 de la mañana a 1 de la tarde, en el horario laboral de lunes a viernes. Este rasgo del repertorio de la protesta costarricense ha empezado a romperse con la convocatoria a algunas marchas vinculadas a organizaciones que luchan por el reconocimiento de derechos de la diversidad sexual, como las Marchas de las Putas que se han realizado, ya sea los fines de semana o en las noches de los viernes. Otras actividades que se inscriben dentro de estas transformaciones han sido las marchas denominadas Invisibles (La Nación, 2012), Incurables (CRhoy.com, 2012), de la Justicia Divina, ni un (In)Justo más (CRhoy.com, 2015), las marchas del Orgullo y las rutas del Beso Diverso (La Nación, 2017).

Por ejemplo, la marcha Invisibles se realizó el sábado 16 de junio de 2012 en horas de la mañana, ante las declaraciones de Justo Orozco, exdiputado evangélico del Partido Renovación Costarricense (PRC), quien señaló la invisibilidad de la población sexualmente diversa. Esta marcha salió del Parque Central y terminó frente a la Asamblea Legislativa. La marcha de los Incurables se realizó el jueves 7 de marzo de 2013, después de las 5 de la tarde, debido a la declaración de interés público de un Congreso de Bioética en el que participaría un médico que afirmaba que la homosexualidad era un problema de salud pública. La marcha salió del parque La Merced y concluyó frente a las instalaciones del Ministerio de Salud (MINSA), en San José.

Las marchas del Orgullo o de la Diversidad, como mejor se les conoce, se realizan en el país desde 2008, siempre un domingo, como parte de la conmemoración mundial del orgullo por la diversidad. Estas marchas salen de La Sabana para culminar en la Plaza de las Garantías Sociales o en la Plaza de la Democracia. La marcha de la Justicia Divina. ¡Ni un (In)Justo más! se realizó el viernes 10 de julio de 2015, después de las 5 de la tarde, por las denuncias de acoso sexual presentadas contra el exdiputado evangélico Justo Orozco, en días previos. Esta marcha concluyó en los Tribunales de Justicia, en horas de la noche.

En ocasiones, las protestas que se organizan los viernes al entrar la noche, comienzan con una concentración que termina en marcha, se divulga información y se da a conocer la demanda planteada, sin que esta se posicione frente a un actor particular, en razón de que se protesta frente a instituciones públicas que ya se encuentran cerradas porque la jornada laboral ha concluido. Por su parte, días como el 25 de noviembre, Día Internacional contra la Violencia hacia las Mujeres, pueden ser muy concurridos si la manifestación es entre semana y el sector público tiene permiso para manifestarse, lo cual no siempre ha sucedido; pero pueden ser muy escuetas si esta fecha es un fin de semana, dada la poca asistencia a este tipo de manifestaciones. Si la
2. En Argentina, por ejemplo, se ha desarrollado un tipo de acción colectiva denominado escrache, en el cual la protesta se realiza frente a las casas de habitación de los funcionarios públicos responsables de determinadas acciones. Un ejemplo de esto fue el Santiagueñazo, protestas realizadas en 1993 en Santiago del Estero, en Argentina. Las personas que participaron en estas protestas se apropiaron de objetos de las instituciones públicas y pertenencias de las casas de los funcionarios que habían sido identificados como corruptos, en un contexto de no pago de los salarios públicos (Auyero, 2004). Em Costa Rica, solo recientemente hemos visto algunas manifestaciones de este tipo, como las realizadas frente a la casa del expresidente de la República, Luis Guillermo Solís (2014- 2018). Sin embargo, este tipo de acciones no son comunes (Araya, 2014). 
conmemoración del 25 de noviembre se realiza en periodo preelectoral es posible que se acerquen grupos vinculados a los partidos políticos contendientes, lo que sucede cada cuatro años. En época lluviosa una protesta culmina cuando empieza a llover, por lo que es difícil que las personas que protestantes se mantengan en el espacio ante estas condiciones climáticas. Aunque no siempre, en muchas ocasiones la protesta acaba con la hora de almuerzo.

Considerando los elementos expuestos, que no pretenden agotar las aristas culturales de la protesta, dado que se busca plantear interrogantes sobre las formas culturales de protestar, la reflexión en torno a cómo, dónde, cuándo y frente a quien se realiza una protesta prevé posicionar no solo una discusión en referencia al actor con el que se quiere dialogar, dado que también plantea un reconocimiento de las potencialidades o los límites culturales y, por ende, políticos, de una protesta.

\section{Del Caribe a San José: encuentros en la calle}

Como se señalaba anteriormente, este artículo busca posicionar una discusión sobre la cultura de la protesta a partir de dos casos particulares. Para esto, seguidamente se presentan algunas ideas en torno a cómo se ubica en el centro del país una conflictividad en la que figuran actores como el Estado y las empresas transnacionales presentes en la región Caribe. Claro está, dicho posicionamiento público vallecentralino no niega las expresiones por las que se ha caracterizado incluso hasta hoy tal conflictividad en el espacio en el que surgió.

Siguiendo la distinción planteada por Auyero, entre memoria y etnografía de la protesta (Auyero, 2004), en este artículo el análisis se plantea a partir de la observación participante y una serie de fotografías tomadas por la autora, después de su participación en las protestas que se explican a continuación. Si bien de cada manifestación se conserva un número significativo de fotografías, por razones de espacio en este artículo se presentan solo algunas, las cuales buscan ilustrar lo argumentado. Como se ha señalado, las fotografías corresponden a protestas realizadas en San José.

La primera de las manifestaciones fue protagonizada por la población bananera afectada por el nemagón. La marcha o concentración fue realizada frente a la Asamblea Legislativa el 12 de abril de 2012. La segunda protesta corresponde a la vigilia por el asesinato de Jairo Mora Sandoval, en 2013; esta manifestación se realizó el 5 de junio a las 5 de la tarde, frente al Ministerio de Ambiente y Energía (MINAE) y fue convocada por organizaciones ambientalistas; posteriormente, la marcha se trasladó a los Tribunales de Justicia en el Circuito Judicial de San José, donde se realizaron actos culturales que terminaron en horas de la noche. Valga señalar que ese día se realizaron múltiples manifestaciones en distintas partes del país. La tercera protesta corres- 
ponde a la marcha denominada Justicia para Jairo Mora, del 29 de enero de 2015, convocada en horas de la mañana frente a los Tribunales de Justicia y que, luego, se dirigió a la Asamblea Legislativa.

Las protestas por la afectación por el nemagón se han desarrollado en el país desde hace varias décadas (Giralt, 1996). De esta forma, desde finales de los años noventa se han registrado acciones colectivas de protesta, cuya demanda inicial fue la aprobación de un proyecto de ley que permitiera la indemnización de la población afectada (Mora, 2013). Estas acciones tuvieron como consecuencia la aprobación del proyecto de ley presentado en la Asamblea Legislativa en 2001, denominado como ley N. ${ }^{\circ} 8130$, Sobre la determinación de Beneficios Sociales y Económicos para la Población Afectada por el DBCP. Sin embargo, las acciones colectivas de protesta no terminaron con la aprobación de la ley, dado que, una vez que esta fue emitida, distintos grupos han reivindicado, hasta hoy, que se les cancele la indemnización, en el marco de lo que la ley permite.

Las primeras tres imágenes que se presentan seguidamente corresponden a la manifestación protagonizada por la población bananera afectada por el DBCP, en solicitud del pago de una indemnización. Como se puede observar en las imágenes 1 y 2 , la protesta estuvo protagonizada, fundamentalmente, por hombres. Manifestaciones similares se han realizado como mecanismo de apoyo para el trabajo parlamentario realizado por el partido Frente Amplio (FA), en particular de los diputados José María Villalta (2010-2014 y 20182022) y Gerardo Vargas (2014-2018). Las protestas han permitido que se demande el pago de las indemnizaciones y la agilización de los trámites para realizar la compensación económica indicada, por parte del Instituto Nacional de Seguros (INS).

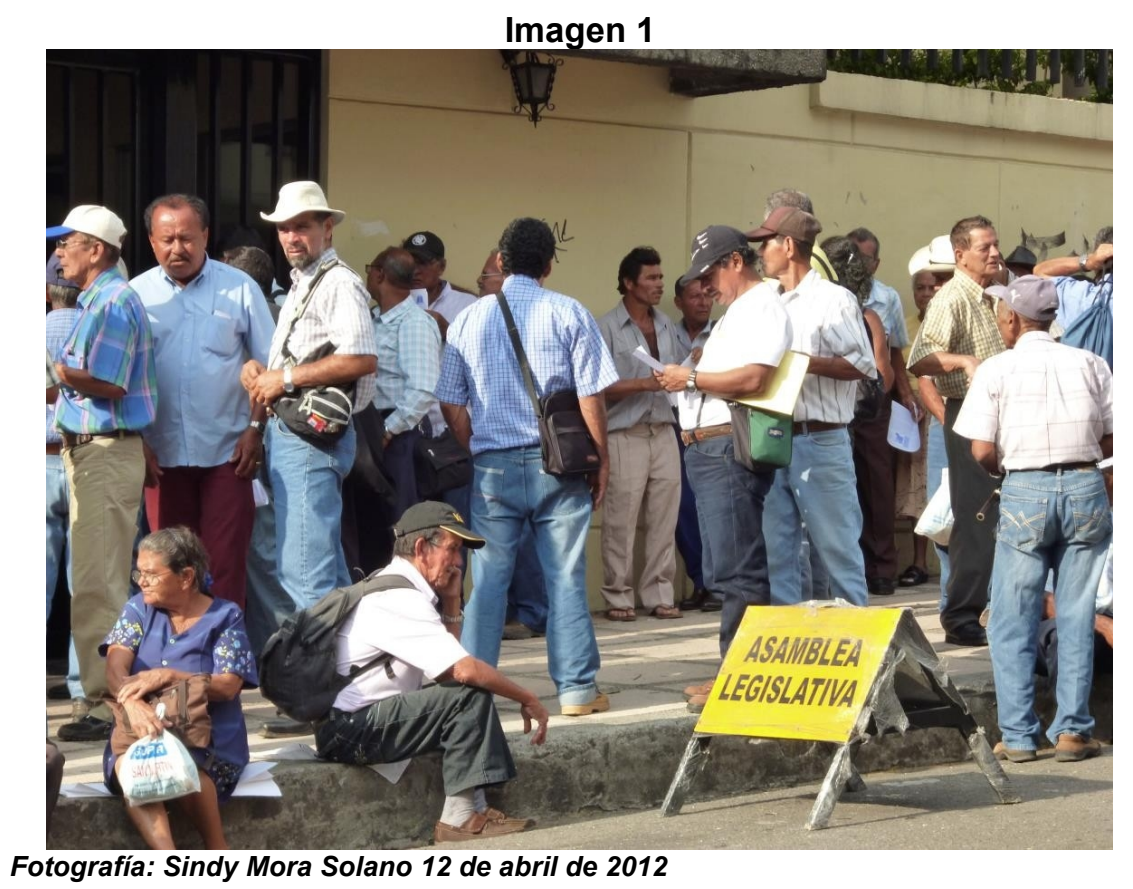


En estas imágenes se observa cómo los alrededores de la Asamblea Legislativa se convirtieron en espacios de encuentro, en el marco de la protesta realizada. Sin embargo, los espacios implicaron un gran desgaste para los grupos movilizados desde el Caribe hasta San José, dado que muchas de las personas que participaron, en un día bastante soleado de abril, no tenían acceso a ningún tipo de alimentación, bebida o agua, así como tampoco a servicios sanitarios, lo que habla de la clase y los recursos movilizados en el marco de la manifestación.

La protesta, convocada por líderes de organizaciones no formales de trabajadores, es decir, no promovida por organizaciones sindicales de bananeros, se mantuvo durante todo el día y terminó en horas de la tarde.

Es importante subrayar que en el caso de esta manifestación, las empresas bananeras desaparecieron como referentes o interlocutores del discurso de quienes fueron afectados por el uso o la exposición al agroquímico. Las demandas planteadas se concentraron en una institucionalidad concreta: la pública; y se podría argumentar que dicha focalización terminó acentuando la llamada impunidad empresarial, señalada anteriormente (Jochnick 2011; Mora 2013). Esto porque al encontrarse la manifestación dirigida contra el Estado, las empresas no fueron mencionadas como actores a los que interpelar como causantes de la afectación por la exposición al agroquímico.

Imagen 2

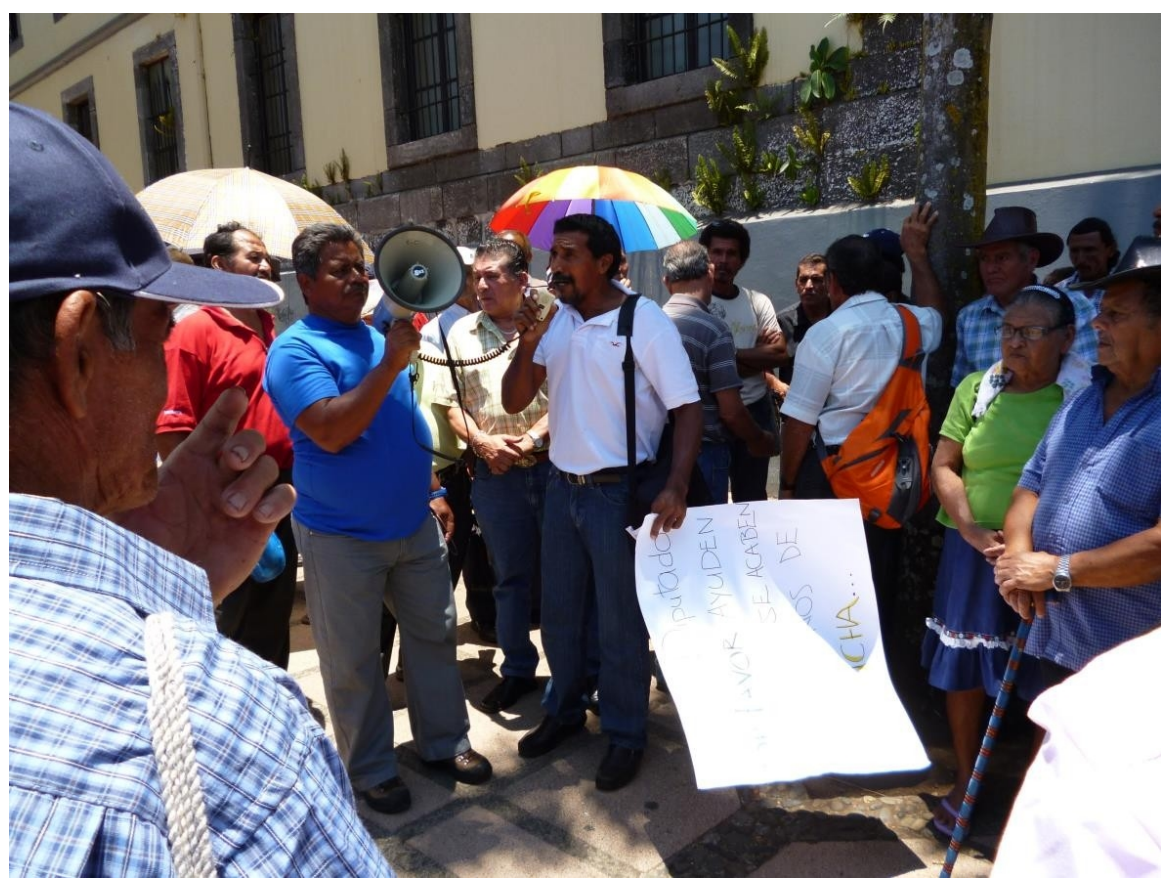

Fotografía: Sindy Mora Solano 12 de abril de 2012 


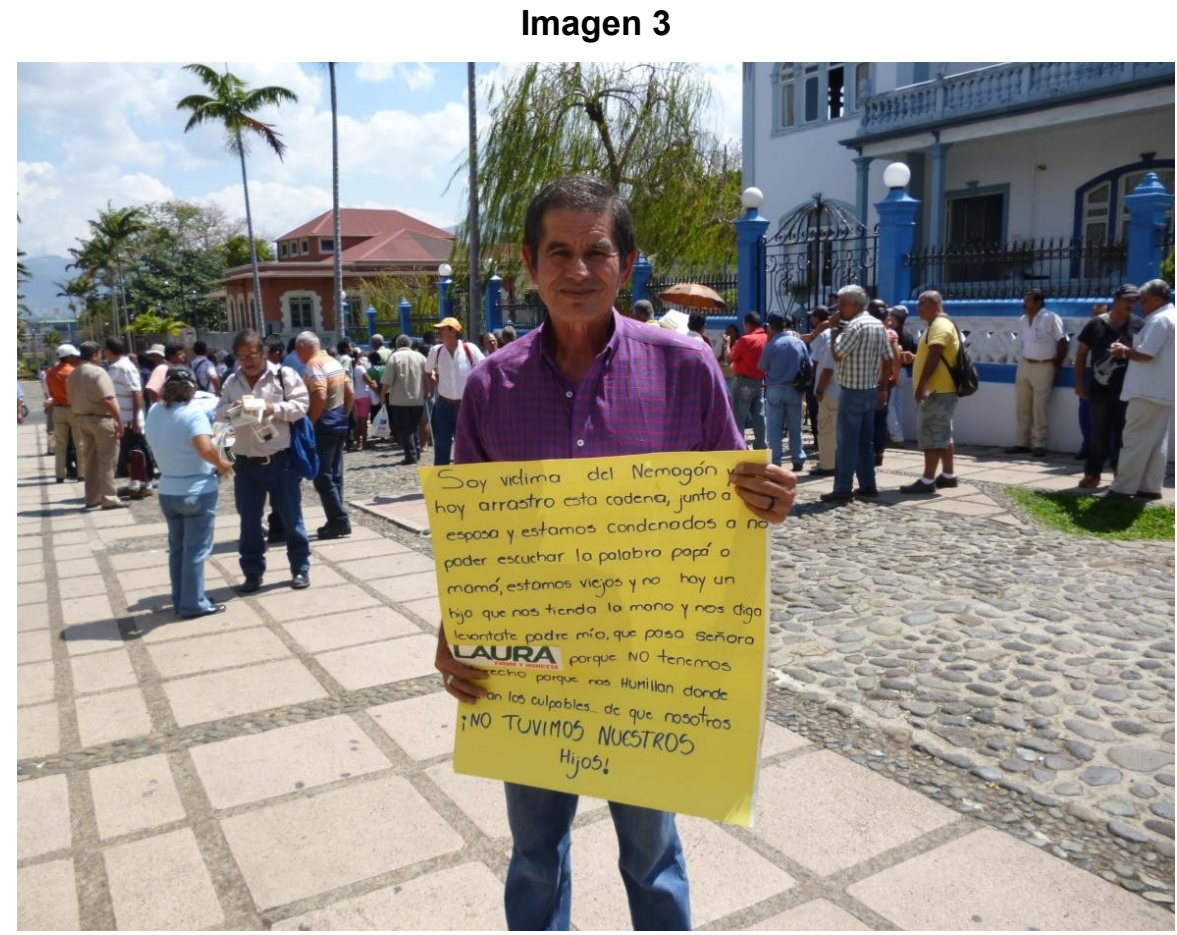

Fotografía: Sindy Mora Solano 12 de abril de 2012

Como muestra, la pancarta de la imagen 3; en esta ocasión, las demandas se dirigieron a la presidenta de la República del momento, Laura Chinchilla Miranda (2010-2014). En la imagen se puede observar el elemento simbólico utilizado, proveniente de la propaganda de la campaña política que dos años antes la había llevado al cargo, con el lema de "Laura: Firme y honesta".

Con respecto al segundo caso elegido, el asesinato de Jairo Mora Sandoval, es preciso señalar que el crimen llenó de indignación a distintos grupos del país (semanario Universidad, 2013). Desde su conocimiento, diversas organizaciones ambientalistas, como la Asociación Costa Rica por Siempre, la Fundación Neotrópica, el Programa Restauración de Tortugas Marinas (PRETOMA) y la Federación Conservacionista de Costa Rica (FECON) manifestaron su repudio ante el asesinato e hicieron un llamado de atención sobre las condiciones de vulnerabilidad en las que estas organizaciones realizaban sus labores. Por consiguiente, solicitaron al Gobierno costarricense condiciones de seguridad, así como el esclarecimiento del asesinato para dar con los responsables del crimen (CRhoy.com, 2013a).

Ante el asesinato de Jairo Mora, las declaraciones de funcionarios gubernamentales no estuvieron exentas de conflicto. Alfio Piva, vicepresidente de la República durante la administración Chinchilla Miranda (2010-2014), señaló en entrevista con la cadena CNN, que el asesinato de Mora había sido "un accidente" ocasionado porque el "muchacho se expuso muchísimo" (Soto, 2013). 


\section{Imagen 4}

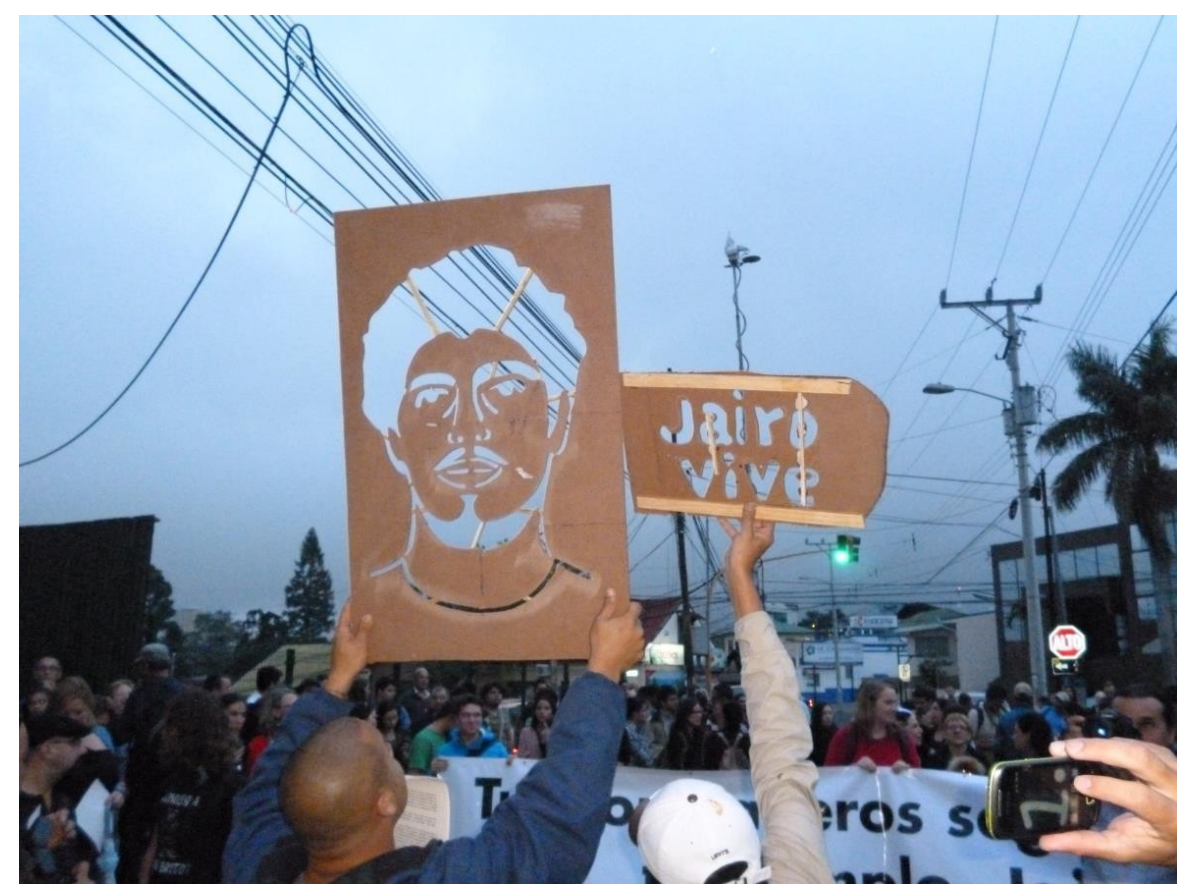

Fotografía: Sindy Mora Solano Vigilia Jairo Mora. 5 de junio de 2013

Tanto los dirigentes de las organizaciones ambientalistas como los diputados de la oposición pidieron una disculpa por parte de Piva, cuyas declaraciones fueron leídas como una estrategia para ocultar la responsabilidad de las instituciones gubernamentales. Por ello, el 5 de junio de 2013, distintas organizaciones convocaron a la realización de una vigilia frente a las instalaciones del Ministerio de Ambiente y Energía (MINAE), en el centro de San José (CRhoy.com, 2013b).

La imagen 4 muestra el punto de partida de la vigilia por el asesinato de Mora, actividad que salió de las instalaciones del MINAE y que se dirigió hacia los Tribunales de Justicia. Durante esta actividad, se demandó una investigación que diera con los responsables del asesinato, una disculpa por parte del vicepresidente de la República por las declaraciones dadas a la cadena CNN, al igual que la creación de un parque en Moín, en la provincia de Limón, que llevara el nombre de Jairo Mora Sandoval. La consigna de la manifestación fue "Jairo vive, vive; la lucha sigue, sigue", lema que fue repetido constantemente durante la actividad.

La imagen 5 muestra las demandas de algunas organizaciones ambientalistas en la búsqueda de justicia para Jairo Mora. En la manifestación, se hizo un Ilamado a no callar ante el asesinato del ambientalista. 


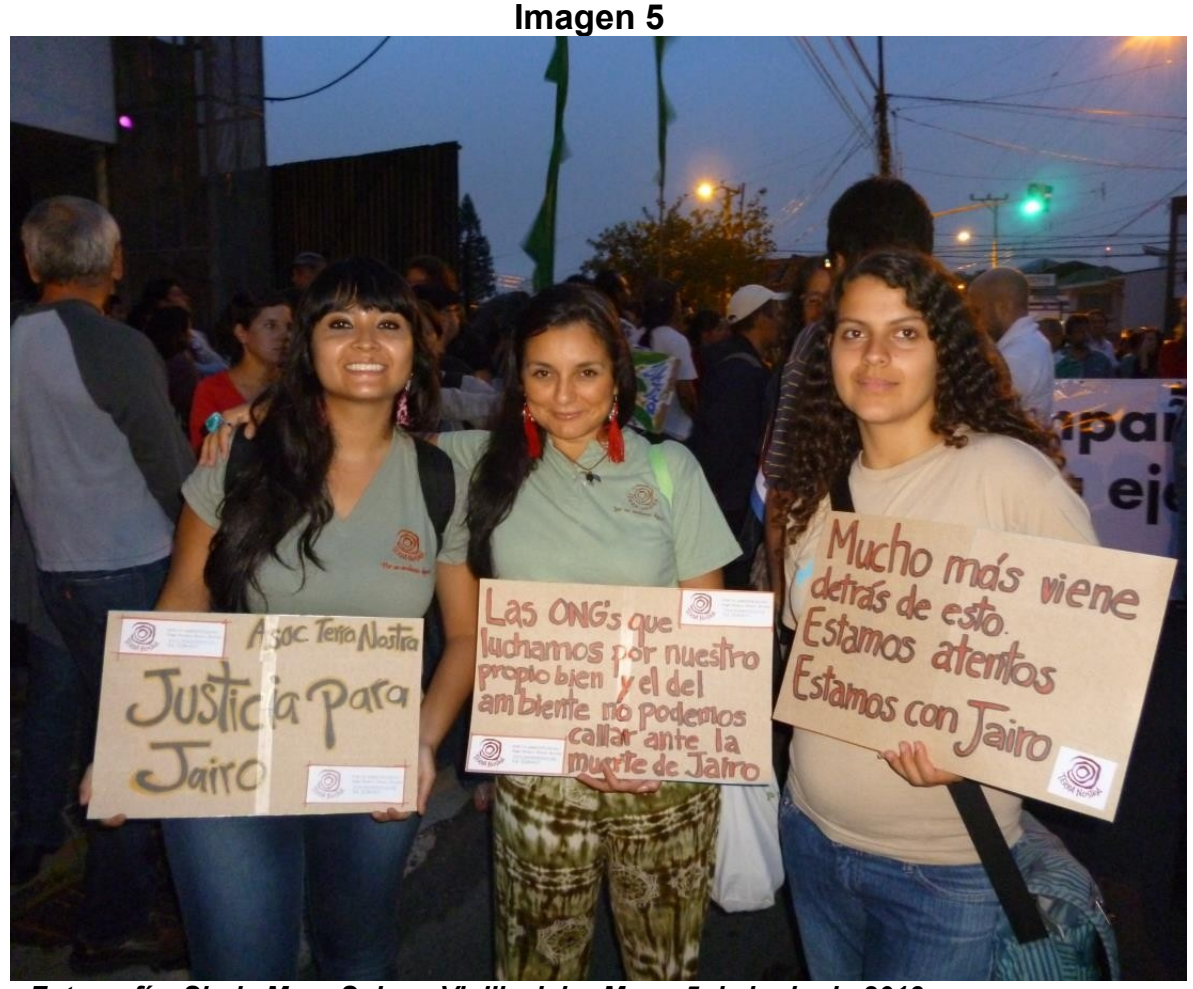

Fotografía: Sindy Mora Solano Vigilia Jairo Mora. 5 de junio de 2013

\section{Imagen 6}

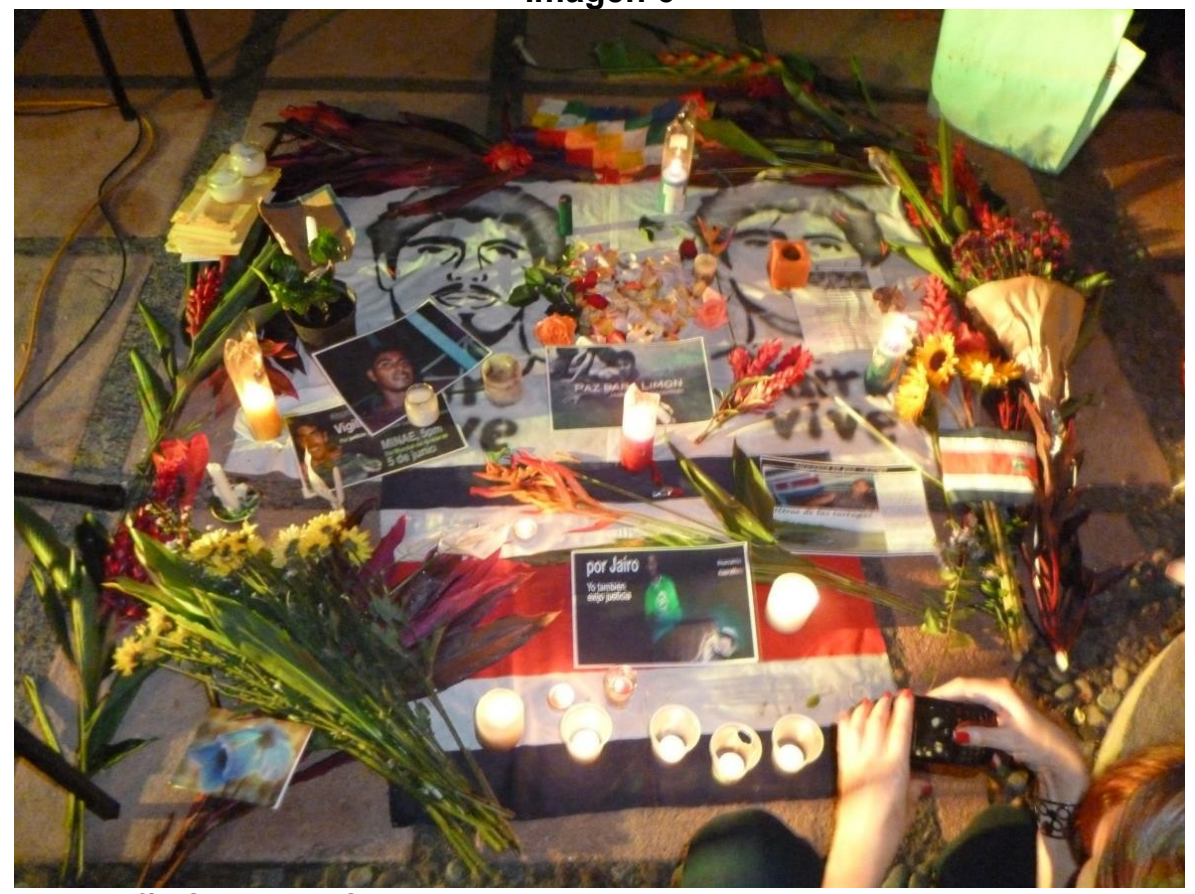

Fotografía: Sindy Mora Solano Vigilia Jairo Mora. 5 de junio de 2013 
En la imagen 6, se muestra el tributo que se realizó a la memoria de Jairo Mora Sandoval durante horas de la noche, una vez que la marcha se posicionó frente al Circuito Judicial, donde primaron las velas y las flores llevadas por quienes participaron en la marcha. Valga señalar un elemento que las fotografías no pueden reproducir y es el sonido de esta manifestación. A diferencia de otras movilizaciones realizadas por las organizaciones ambientalistas, donde siempre hay consignas alegres, canciones, música, baile y risas, esta fue una marcha silenciosa, en la que no hubo instrumentos musicales ni bailes.

Quienes participaron en esta manifestación guardaron un profundo silencio hasta llegar a los Tribunales de Justicia, ya que esta fue una actividad similar a un silencioso funeral, que, además, se vio acompañado por la lluvia. A pesar de esto, la lluvia no detuvo a quienes se manifestaban. Únicamente al empezar los actos culturales fue posible escuchar composiciones realizadas exclusivamente para Jairo, como lo fue la canción "Ocupamos ayuda y pronto", compuesta por el cantautor Manuel Monestel (Manuel Monestel 2013).

Como se observa en la imagen 7, mediante sus pancartas, algunas personas establecieron relaciones entre el asesinato del ambientalista y la concesión de la construcción de la Terminal de Contenedores de Moín, infraestructura entendida como sinónimo de muerte. Sin embargo, la mayor parte de los mensajes vistos esa noche se encontraban dirigidos a la institucionalidad pública, con su reclamo de justicia. Los Tribunales de Justicia se encontraban cerrados a la hora a la que se convocó la vigilia, encontrándose la institución pública solitaria y desdibujándose, el papel de las empresas privadas en este proceso. Esta manifestación finalizó en horas de la noche, tras una serie de actividades artísticas.

Un mes después del asesinato de Jairo Mora Sandoval, organizaciones como la FECON denunciaron la inexistencia de acciones por parte del Organismo de Investigación Judicial (OIJ) que llevaran a la identificación y la captura de los culpables del asesinato (Carvajal, 2013). Posteriormente, a principios de agosto de 2013, se había detenido a seis personas por el crimen de Mora (Sancho 2013) y el 3 de noviembre de 2014, es decir, un año después, empezó el juicio en el Tribunal Penal de Limón (Mena, 2014).

A principios de 2015, la noticia de que el Tribunal correspondiente había absuelto a todos los implicados en el juicio levantó los ánimos de muchas organizaciones sociales, lo que se convirtió en noticia a nivel internacional (Mena, 2015a; Murillo, 2015). Las fotografías que se presentan seguidamente corresponden a la marcha Justicia para Jairo, que se realizó el 29 de enero de 2015 frente a los Tribunales de Justicia, en la provincia de San José, y que, posteriormente, se dirigió a la Asamblea Legislativa. 


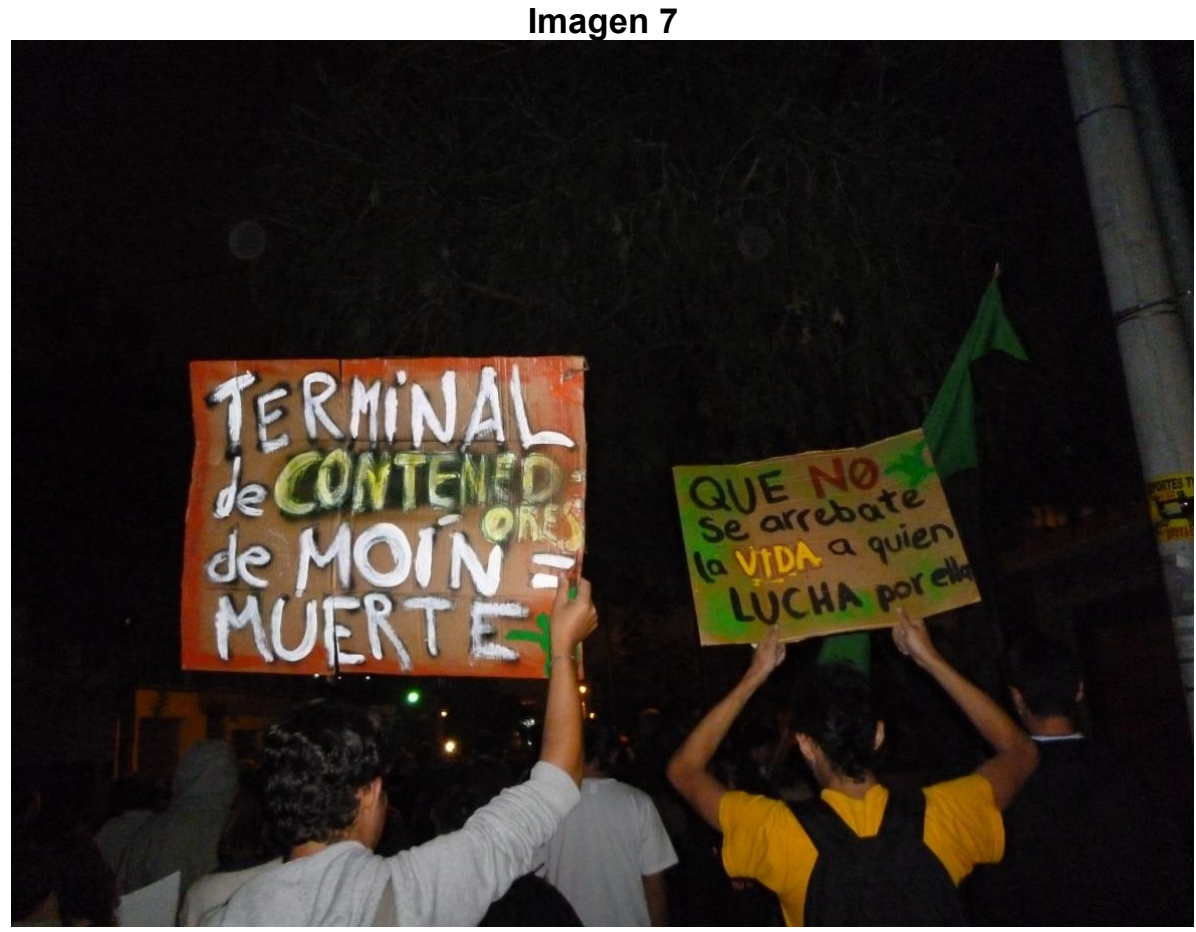

Fotografía: Sindy Mora Solano Vigilia Jairo Mora. 5 de junio de 2013

Como se señalaba, la marcha se realizó luego del conocimiento de la absolutoria de los sospechosos del crimen, en un contexto en el que la Fiscalía General de la República y el OIJ fueron acusados de un inadecuado proceso de recolección y presentación de las pruebas (Barquero, 2015; Mena, 2015b). Por ello, esta fue una protesta en la cual se expresó el malestar cultural en torno a los escándalos de corrupción de los últimos años, el que no nece sariamente se ha hecho manifiesto en otras coyunturas políticas mediante acciones articuladas de protesta social y que también constituye otro de los rasgos del repertorio de la protesta costarricense.

En este sentido, en la protesta del 29 de enero de 2015, la corrupción se erigió como una de las principales razones con las que se explicó el proceder de la Fiscalía General de la República, como se puede observar en las pancartas de las imágenes 8 y 9 . Las acusaciones se lanzaron contra el exfiscal general de la República, Jorge Chavarría, quien en declaraciones a la prensa admitió que el Ministerio Público había cometido errores en la recolección de las pruebas para sancionar a los autores materiales del crimen de Jairo Mora Sandoval (Rojas, 2015; Mena, 2015c).

Por ello, en las imágenes que se presentan seguidamente, una de las principales entidades interpeladas fue la Fiscalía General de la República, acusada de negligencia y corrupción. 
Imagen 8. Marcha Justicia para Jairo Mora. 29 de enero de 2015

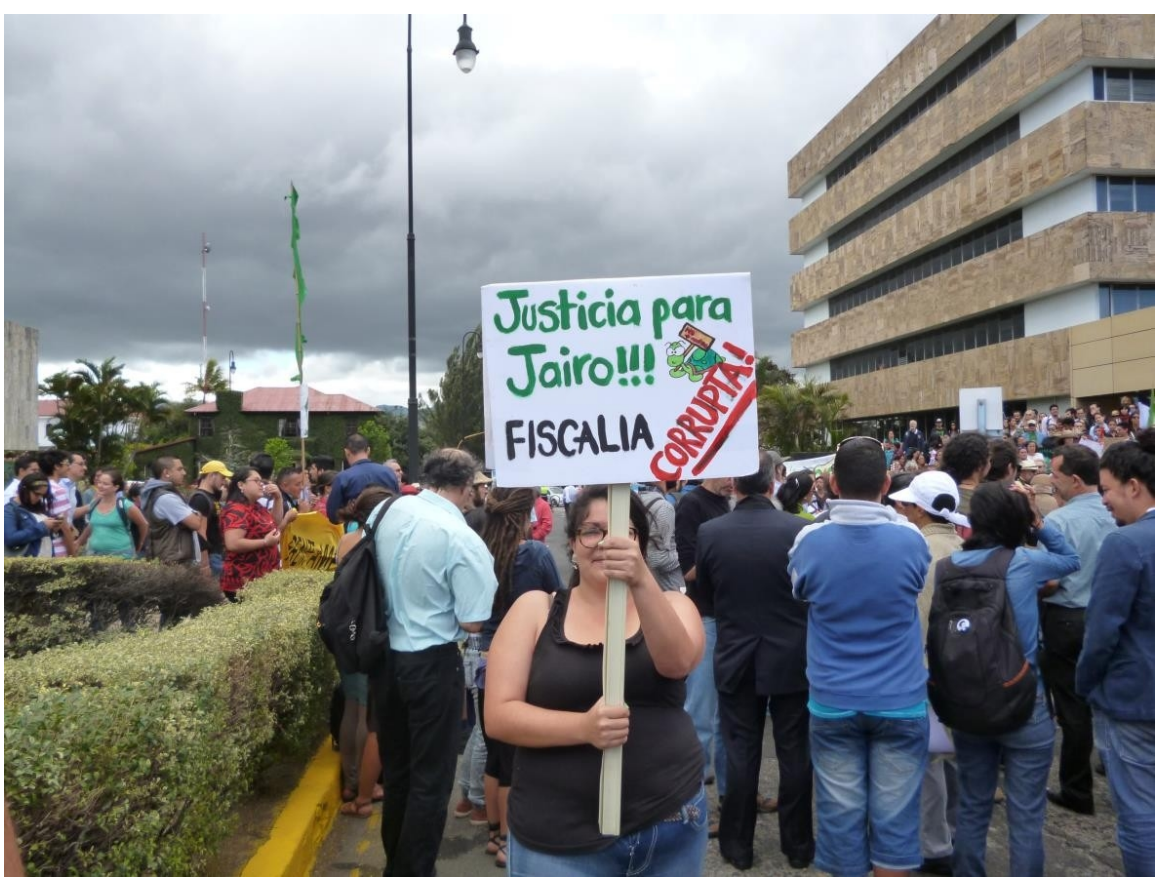

Fotografía: Sindy Mora Solano

Imagen 9. Marcha Justicia para Jairo Mora. 29 de enero de 2015

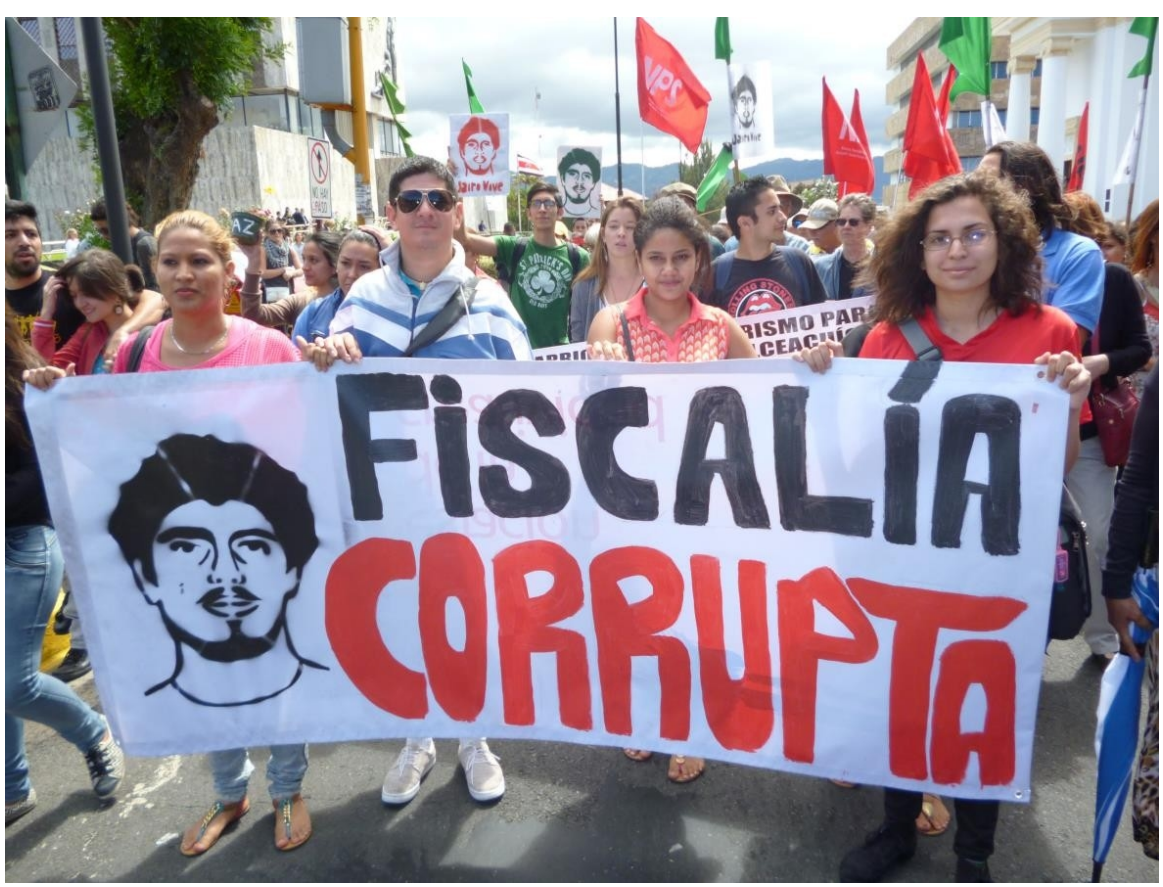

Fotografía: Sindy Mora Solano 
Una vez dejado un ataúd en la entrada de los Tribunales de Justicia, con los nombres de los ambientalistas asesinados en el país, la marcha se dirigió hacia la Asamblea Legislativa.

Desde la perspectiva de quienes se manifestaron, la absolución de los sospechosos de cometer el asesinato de Jairo Mora Sandoval evidenciaba que el Ministerio Público había actuado de manera corrupta, con negligencia y promoviendo la injusticia, haciendo un juego de palabras en donde se podían identificar las siglas del Organismo de Investigación Judicial (OIJ), como se observa en letras escritas en color rojo en la pancarta de la imagen 10. De esto daba fe, A. Propósito, nombre responsable que firmaba la impunidad promovida por el Ministerio Público, como se expresa en dicha pancarta, que el proceso de omisión y descuido de las pruebas fue hecho de manera intencional.

Imagen 10. Marcha Justicia para Jairo Mora. 29 de enero de 2015

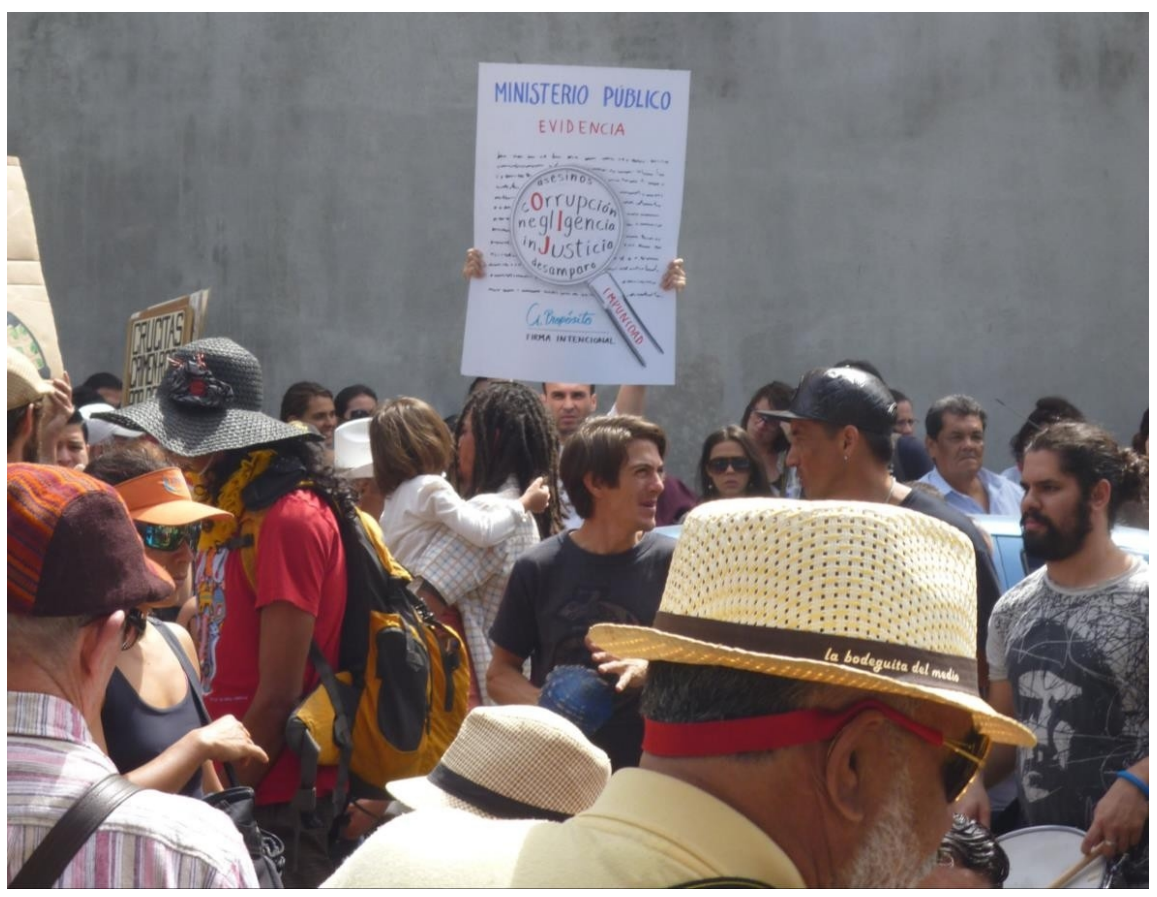

Fotografía: Sindy Mora Solano

Como se ha planteado para el caso de las protestas por la afectación por el nemagón, el posicionamiento en San José de una conflictividad surgida en la región Caribe y en la que son primordiales los actores de carácter privado, hace que tal conflictividad se sitúe frente a las instituciones públicas, como la Asamblea Legislativa, poniendo en un segundo plano las responsabilidades privadas inmiscuidas en el conflicto, no solo porque las demandas se encuentran dirigidas a la institucionalidad pública, sino porque en el discurso 
posicionado en el espacio público hay pocos referentes a los actores privados. Es decir, estos últimos se encuentran en cuanto referentes ausentes de las manifestaciones. Valga señalar que con tal afirmación no se pretende negar la función tan importante del Estado en la producción y en la concreción de determinadas conflictividades; tampoco con ello se busca eximir de responsabilidades a los representantes estatales en cuanto a la reproducción de los procesos de desigualdad (Mora, 2013).

Sin embargo, asumir que solo el Estado es el responsable permite establecer preguntas en torno al carácter paternalista que persiste en la gestión de los conflictos en el país, lo mismo que las dificultades existentes para sentar las responsabilidades correspondientes de los actores de carácter privado.

En las imágenes 11 y 12 se puede observar el fin de la concentración que se realizó ese día 29 de enero del 2015 frente a la Asamblea Legislativa.

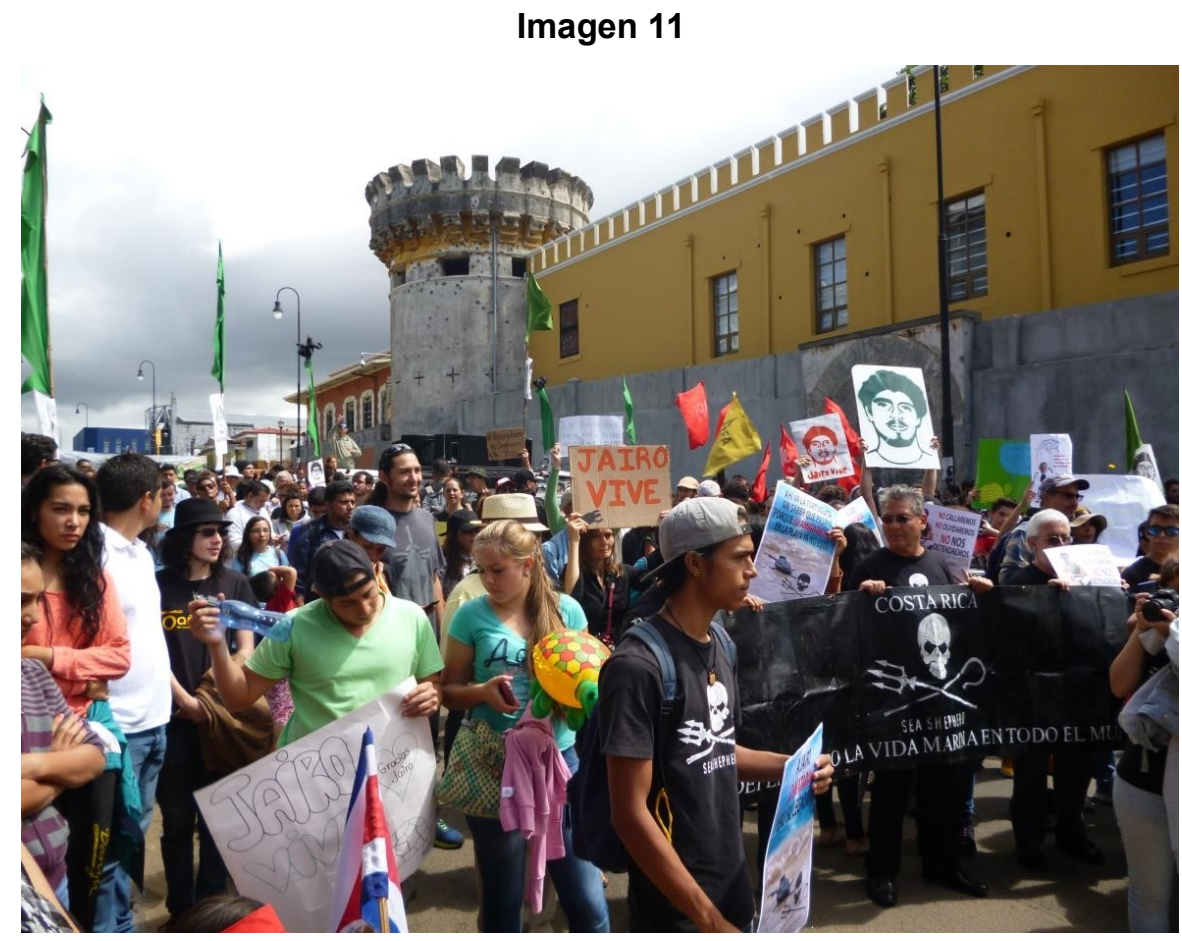

Fotografía: Sindy Mora Solano 
Imagen 12. Marcha Justicia para Jairo Mora. 29 de enero de 2015

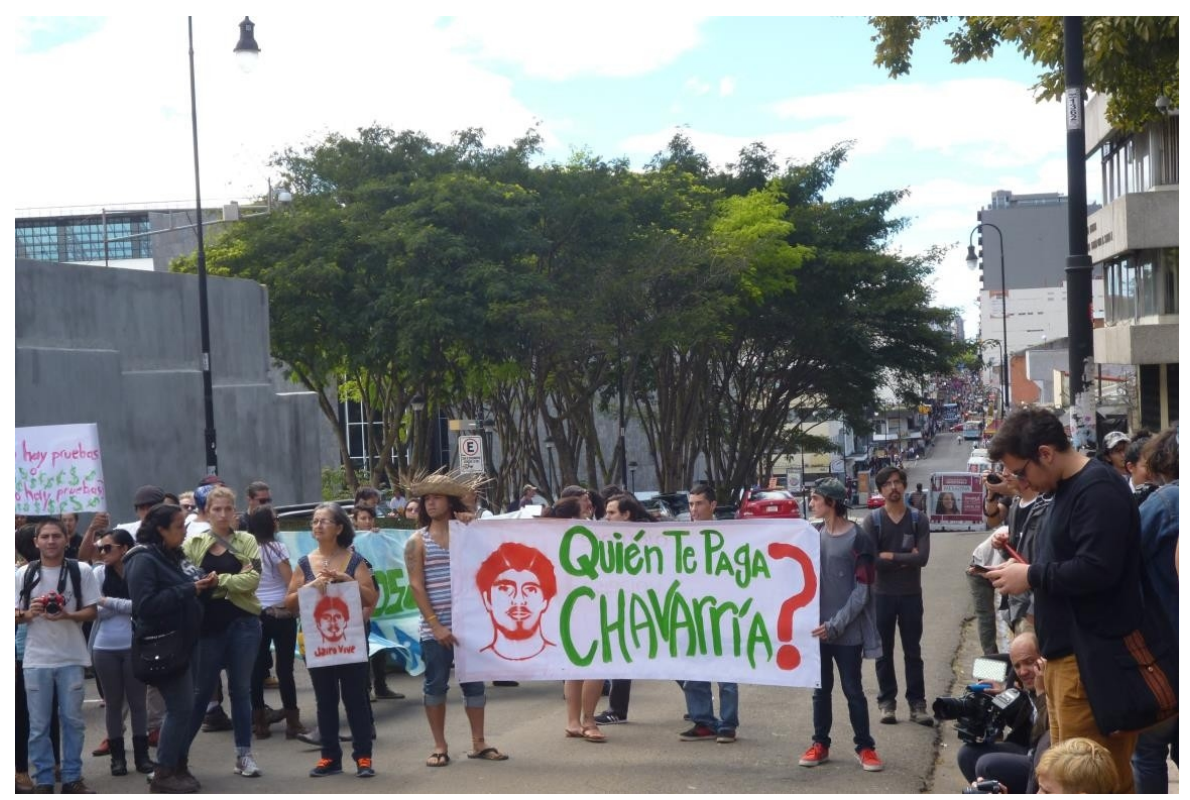

Fotografía: Sindy Mora Solano

Para finalizar, se debe señalar que en un segundo juicio por el asesinato del ambientalista, celebrado en marzo de 2016, fueron condenadas cuatro personas con la pena máxima permitida en el país, que corresponde a 50 años (Alfaro, 2016). A pesar de que en esta ocasión cuatro personas fueron identificadas como responsables del crimen, una variedad de organizaciones y actores políticos manifestaron su inconformidad con la sentencia, ya de acuerdo con su perspectiva, la impunidad persiste, a pesar del dictamen judicial (Informativo Mesoamericano Voces Nuestras 2015a, 2016).

Con el asesinato de Mora Sandoval, dirigentes ambientalistas han señalado la necesidad de crear una Comisión de Justicia y Verdad Ambiental que permita esclarecer lo sucedido en el caso del crimen en cuestión, pero también para atender los casos de otros asesinatos de ambientalistas que quedaron impunes (Álvarez, 2013, 2015 y 2016b).

A cinco años del asesinato de Jairo Mora Sandoval, tanto Álvaro Sagot, Mauricio Álvarez como Nicolás Boeglin cuestionaron la realización de una serie de megaproyectos en Moín, en la provincia de Limón, lugar en el que fue asesinado Mora, lo que evidencia, desde su perspectiva, que la impunidad continúa (Informativo Mesoamericano Voces Nuestras, 2015b; Álvarez, 2018; Boeglin, 2018).

De la misma manera, estos ambientalistas han cuestionado la inacción estatal en cuanto a la recomendación de establecer una Comisión de Justicia y Verdad Ambiental que permita identificar a los autores intelectuales del crimen, dado que la magnitud de los proyectos que empiezan a realizarse en 
este espacio evidencia la necesidad de seguir otras hipótesis de investigación judicial, más allá de la que señala que Jairo Mora se enfrentó a recolectores de huevo de tortuga.

Hoy, los ambientalistas han denunciado cómo Costa Rica se ha convertido en un país turísticamente no ético (Álvarez, 2016a), donde, a pesar de las sanciones penales establecidas en el juicio por el asesinato de Jairo Mora Sandoval, continúa la contaminación y la destrucción de la vida en el Caribe costarricense y, con ello, la impunidad.

\section{Reflexiones finales}

A partir de la discusión presentada, seguidamente se exponen algunas reflexiones en torno a la cultura de protesta y las conflictividades que se posicionan desde la región Caribe frente a la institucionalidad pública del Valle Central. La primera idea para discutir se relaciona con el hecho de que los espacios utilizados por los actores colectivos con el fin de plantear sus demandas en torno a los procesos de desigualdad e injusticia vividos en la Región Caribe son los espacios culturalmente predominantes en el repertorio de la protesta costarricense.

Es decir, en estas protestas no necesariamente se han creado nuevos lugares de encuentro, dado que este tipo de manifestaciones políticas se encuentran dirigidas a aquellos actores que tradicionalmente se han pensado como los interlocutores legítimos de la protesta social: los vinculados al Gobierno y sus instituciones. Así, las manifestaciones se desarrollaron en los espacios tradicional y culturalmente establecidos para tal fin.

En ese sentido, y como segunda idea para la reflexión, las demandas presentadas cumplen como objetivo interpelar al Estado y a las instituciones del Gobierno como el principal actor responsable, lo que provoca que se desdibuje la responsabilidad de los actores de carácter privado. En los discursos de las manifestaciones de protesta analizados, persiste la idea de que el Estado es la entidad reguladora de las conflictividades y, a pesar de que en ocasiones se acusa al Estado de su complicidad en determinados procesos, dichos señalamientos no construyen otro lugar para el Estado, dado que las acciones de protesta continúan centralizando las demandas frente a este, como entidad legítima para la solución de los conflictos. Por ende, es central preguntarse, mediante procesos de investigación de largo alcance, en torno al papel que ha jugado el Estado en la construcción de las reivindicaciones y las estrategias colectivas de las organizaciones y grupos de protesta para solucionar determinadas problemáticas.

Relacionado con lo anterior, y como tercera idea para la discusión, es fundamental plantear que en las manifestaciones analizadas las responsabilidades de los actores privados quedaron diluidas o no abiertamente visibilizadas. Las responsabilidades en torno a las extracciones de recursos, los procesos 
de contaminación, la producción de enfermedades y las muertes surgidas en la región Caribe fueron endosadas a un Estado, como regulador de los conflictos, donde las empresas privadas y otros poderes asociados a estos diferendos no tuvieron lugar. Así pues, al no nombrarse con toda propiedad los poderes privados que se encuentran detrás de estas problemáticas, desde las acciones de protesta estudiadas se contribuyó con la impunidad empresarial que rodea tales procesos, en el sentido apuntado por Jochnick. Desde tal perspectiva, es preciso registrar e investigar con más detenimiento los conflictos que se encuentran dirigidos a las empresas privadas, a fin de comprender qué contextos y recursos políticos posibilitan las impugnaciones al poder privado. En esta agenda de investigación puede ser relevante preguntarse por los recursos políticos necesarios para hacer más visible el poder empresarial que se encuentra detrás de las problemáticas en donde este tipo de actores tienen injerencia y responsabilidad.

En este sentido, y como una cuarta idea para el debate, es crucial emprender un análisis profundo de los mecanismos de impunidad empresarial que permitan comprender cómo los actores de carácter privado quedan eximidos de sus responsabilidades en conflictividades como las señaladas. Los casos de la afectación por el DBCP y la muerte del ambientalista Jairo Mora Sandoval son dos ejemplos de cómo los intereses privados son fundamentales en la estructuración de procesos de desigualdad y violencia política, sin que se hayan establecido sanciones contra este tipo de actores. Igualmente, resulta fundamental comprender cómo las subjetividades y acciones de protesta dejan sin cuestionar a esos actores de carácter privado.

A pesar de lo anterior, afortunadamente, las protestas analizadas le han dado un lugar al dolor colectivo, combatiendo el potencial olvido de los casos estudiados. Si bien el objetivo fundamental de esas manifestaciones no es brindar información, formar conciencia en otros sectores de la población ni dar a conocer una situación de injusticia, gracias a las protestas realizadas fue posible posicionar en el espacio público las consecuencias de la desigualdad y de la violencia política, patentes en determinadas regiones del país, que, como señalan Álvarez, Dagnino y Escobar, son ejes centrales en las disputas por los sentidos de las protestas.

Mientras que la manifestación de la población afectada por el nemagón, evidencia cómo se posicionó en el Valle Central una protesta marcada por recursos políticos limitados, donde la clase social estructura las estrategias de lucha. Con más recursos políticos, entre los que destaca la indignación ante el asesinato y el proceder de las instituciones administradoras de justicia, las manifestaciones por la muerte de Jairo Mora Sandoval, por su parte, posicionaron la necesidad de esclarecer este y otros asesinatos sobre los que el movimiento lleva cuenta, así como la demanda de protección a los ambientalistas, fuertemente estigmatizados y criminalizados en este país. Los procesos de desigualdad se expresan en el cuerpo, en el desarrollo de enfermedades, en las condiciones de lucha que se desarrollan frente a la persecución y la muerte. La población afectada por el DBCP y el asesinato de Jairo Mora Sandoval son evidencias de ello. 


\section{Bibliografía}

Alfaro, Josué. 2016. «Condenan a cuatro acusados por el asesinato de Jairo Mora». Semanario Universidad, 29 de marzo de 2016. https://semanariouniversidad.com/ultima-hora/condenan-cuatroacusados-asesinato- jairo-mora

Álvarez, Mauricio. 2013. «Los ambientalistas exigimos respeto, René Castro». CRhoy.com,10 de julio de 2013. http://www.crhoy.com/archivo/opinion-los-ambientalistas- exigimosrespeto-rene-castro/opinion/el-lector-opina/.

Álvarez, Mauricio. 2015. «Jairo Mora: ¿se hará justicia?» El País CR, 25 de enero de 2015. https://www.elpais.cr/2015/01/25/jairo-mora-se-harajusticial.

Álvarez, Mauricio. 2016a. «Jairo: Justicia con impunidad». EIPaíscr.com, 29 de marzo de 2016. http://www.elpais.cr/2016/03/29/si-declaradosculpables-pero-anoche-se-difundia-un- video-de-una-tortuga-vivaamarrada-a-un-carro-en-movimiento-siendo-arrastrada- por-una-callede-lo-que-pareciera-ser-moin-de-manera-muy-similar-a-l/.

Álvarez, Mauricio. 2016b. «Jairo Mora y el terrorismo en Costa Rica». Informa-tico.com, 7 de junio de 2016. http://informa-tico.com/7-062016/jairo-mora-terrorismo-costa-rica.

Álvarez, Mauricio. 2018. «5 años Jairo Mora ¿cómo destruir su legado?» Surcos Digital, 2 de junio de 2018. Disponible en: http://surcosdigital.com/5-anos-jairo-mora-como-destruir-su- legado/.

Álvarez, Sonia, Evelina Dagnino, y Arturo Escobar. 1998. Cultures of Politic. Politics of Cultures. Re-visioning Latin America Social Movements. Estados Unidos: Westview Press.

Araya, Alexandra. 2014. «Vecinos de Alajuelita realizan vigilia frente a casa de presidente Luis Guillermo Solís». La Nación, 15 de agosto de 2014. http://www.nacion.com/nacional/vivienda/Vecinos-Alajuelita-LuisGuillermo-Solis_0_1433056756.html.

Auyero, Javier. 2002. La protesta. Retratos de la beligerancia popular en la Argentina democrática. Libros del Rojas, Universidad de Buenos Aires. Argentina.

Auyero, Javier. 2004. Vidas Beligerantes. Dos mujeres argentinas, dos protestas y la búsqueda de reconocimiento. Argentina: Editorial de la Universidad Nacional de Quilmes. 
Barquero, Karla. 2015. «Protestan en Tribunales de San José por caso de Jairo Mora; piden renuncia de Fiscal». Crhoy.com, 29 de enero de 2015. http://www.crhoy.com/archivo/protestan-en-tribunales-de-sanjose-por-caso-de-jairo- mora-piden-renuncia-del-fiscal/.

Boeglin, Nicolás. 2018. «A cinco años de la muerte de Jairo Mora y varias preguntas sin responder». Surcos Digital, 2 de junio de 2018. http://surcosdigital.com/a-cinco-anos- de-la-muerte-de-jairo-mora-yvarias-preguntas-sin-responder/.

Bohme, Susanna. 2012. "The Role of the Nation-State in the Transnational History of DBCP». En Dangerous Trade. Histories of Industrial Hazard across a globalizing World, Sellers, Christopher; Mellig, Joseph. Philadelphia: Temple University Press.

Carvajal, Erick. 2013. "Jairo Mora: 30 días después, su muerte sigue impune». Crhoy.com, 1 de junio de 2013. http://www.crhoy.com/archivo/jairo-mora-30-dias-despues-su- muertesigue-impune/.

Cohen, Deborah, y Lessie Frazier. 2004. «México 68: hacia una definición del espacio del movimiento. La masculinidad heroica en la cárcel y las "mujeres" en la calle». Estudios sociológicos 22 (66): 591-623.

CRhoy.com. 2012. "Convocan a "manifestación de incurables" en defensa de los DD.HH». CRhoy.com, 20 de febrero de 2012. http://www.crhoy.com/archivo/convoca-a- manifestacion-de-incurablesen-defensa-de-los-dd-hh/.

CRhoy.com. 2013a. "Organizaciones ambientales lanzan un "grito de auxilio"». CRhoy.com, 3 de junio de 2013. http://www.crhoy.com/archivo/organizaciones-ambientales-lanzan-ungrito-de-auxilio/.

CRhoy.com. 2013b. «Decenas se unen a vigilia en honor a ambientalista Jairo Mora». CRhoy.com, 5 de junio de 2013. http://www.crhoy.com/archivo/decenas-se-unen-a- vigilia-en-honor-aambientalista-jairo-mora/.

CRhoy.com. 2015. «jNi un (in) Justo más! Marcharán para exigir justicia pronta en caso de exdiputado Orozco». Crhoy.com, 7 de julio de 2015. http://www.crhoy.com/archivo/ni-un-in-justo-mas-marcharan-para-exigirjusticia- pronta-en-caso-de-exdiputado-orozco/.

Galvis, María Clara. 2011. «La obligación estatal de prevenir las conductas de particulares contrarias al derecho internacional». Aportes DPLF. Revista de la Fundación para el Debido Proceso 4 (15): 47-48. 
Giralt, Marielos. 1996. «La problemática ética del uso del DBCP en Costa Rica» XXXIV (83- 84): 415-21.

Gómez, Cándida. 2013. «Tras los rostros de la lucha bananera en Nicaragua: organización, identidad y liderazgo local». Anuario de Estudios Centroamericanos 39: 167-209.

Informativo Mesoamericano Voces Nuestras. 2015a. «Denuncian que asesinato de Jairo Mora fue un crimen político». http://www.vocesnuestras.org/2015-01-30/vn- noticias/denuncianasesinato-jairo-mora-fue-crimen-politico.

Informativo Mesoamericano Voces Nuestras. 2015b. «En Costa Rica: Aumenta oposición al mega puerto en el Caribe costarricense en manos de compañía holandesa APM Terminals».

http://www.vocesnuestras.org/2015-02-27/costa-rica/costa-rica-aumentaoposicion- mega-puerto-caribe-costarricense-manos-compania.

Informativo Mesoamericano Voces Nuestras. 2016. «En Costa Rica: "Se hizo justicia parcial por el asesinato de Jairo Mora" coinciden ecologistas costarricenses». http://www.vocesnuestras.org/2016-04- 01/costarica/costa-rica-se-hizo-justicia-parcial-asesinato-jairo-mora-coincidenecologistas.

Isla, Ana. 2002. «Forcejeo por mantener el agua limpia y el sustento diario: La minería canadiense en Costa Rica en la era del desarrollo sustentable/globalización». Revista de Ciencias Sociales, n. ${ }^{\circ}$ 97: 13747.

Jochnick, Chris. 2011. «¿Qué implicaciones tiene la sentencia contra Chevron por $\$ 18$ millones de dólares?» Aportes DPLF. Revista de la Fundación para el Debido Proceso 4 (15): 12-15.

La Nación. 2012. «Multitud caminó en Marcha de los Invisibles y "limpió" el Congreso». La Nación, 16 de junio de 2012. http://www.nacion.com/archivo/Multitud-camino-Marcha- InvisiblesCongreso_0_1275072634.html.

La Nación. 2017. «Memoria de los movimientos LGBTI en Costa Rica: avances, hitos y deudas». La Nación, 1 de julio de 2017. https://www.nacion.com/viva/cultura/memoria-de-los-movimientos-lgbtien-costa-rica- avances-hitos-ydeudas/44SADM6RTNDWJHJWDTXAGYCASU/story/.

Lebuis, Veronique. 2011. «Derechos humanos y empresas transnacionales: ¿podrán los tribunales canadienses juzgar a las empresas canadienses 
por los daños causados en el exterior?» Aportes DPLF. Revista de la Fundación para el Debido Proceso 4 (15): 19-23.

Maihold, Günther. 2012. "La "política del dolor" ante la inacción del Estado en materia de seguridad. Los casos de Blumberg en Argentina y Sicilia en México». Nueva Sociedad, n. ${ }^{\circ} 240: 188-200$.

Manuel Monestel. 2013. Ocupamos ayuda y pronto. https://www.youtube.com/watch?v=RORMd6Q_xw8.

Mena, Fabio. 2014. «Juicio por asesinato de joven ambientalista Jairo Mora empezó esta mañana». CRhoy.com, 3 de noviembre de 2014. http://www.crhoy.com/archivo/juicio- por-asesinato-de-jovenambientalista-jairo-mora-empezo-esta-manana/.

Mena, Fabio. 2015a. «Tribunal Penal de Limón absolvió a sospechosos de asesinar al ambientalista Jairo Mora». Crhoy.com, 26 de enero de 2015. http://www.crhoy.com/archivo/tribunal-penal-de-limon-absolvio-asospechosos-de- muerte-de-ambientalista-jairo-mora/.

Mena, Fabio. 2015b. «Impune: errores del Ministerio Público dejan en libertad a sospechosos de asesinar a Jairo Mora». Crhoy.com, 27 de enero de 2015. http://www.crhoy.com/archivo/impune-errores-del-ministeriopublico-dejan-en- libertad-a-sospechosos-de-asesinar-a-jairo-mora/.

Mena, Fabio. 2015c. «Grupos se unen para protestar por absolutoria en juicio de Jairo Mora; pedirán destitución del Fiscal». Crhoy.com, 29 de enero de 2015. http://www.crhoy.com/archivo/grupos-se-unen-para-protestarpor-absolutoria-en- juicio-de-jairo-mora-y-pediran-destitucion-del-fiscal/.

Mora, Sindy. 2008. "Diez años de acciones colectivas en Costa Rica». Revista Centroamericana de Ciencias Sociales V (8): 131-68.

Mora, Sindy. 2011. "Las disputas por los sentidos de lo político en Costa Rica: hacia un balance de las luchas populares de la presente década». En Una década en movimiento. Luchas populares en América Latina en el amanecer del siglo XXI, editado por M Modonesi y J Rebón. Argentina: Consejo Latinoamericano de Ciencias Sociales (CLACSO), Prometeo Libros.

Mora, Sindy. 2013. «Reflexiones para el análisis comparativo de movimientos sociales: el caso de extrabajadoras y extrabajadores bananeros afectados por el nemagón en Costa Rica y Nicaragua». Anuario de Estudios Centroamericanos 39: 211-32.

Mora, Sindy. 2015. Las luchas por la defensa del derecho a la salud en Costa Rica, durante el año 2012. Inédito. 
Murillo, Álvaro. 2015. «Liberados por falta de pruebas los acusados de matar a Jairo Mora». Elpaís.com, 26 de enero de 2015.

http://internacional.elpais.com/internacional/2015/01/26/actualidad/14223041 32 3183 14.html.

Navarro, Santiago. 2013. «Turismo e inmigración en Playa Matapalo, Sardinal, Costa Rica. Resistencias comunitarias y laborales». Anuario de Estudios Centroamericanos 39: 263-87.

Programa Estado de la Nación (PEN). 2017. Estado de la Nación en Desarrollo Humano Sostenible. Costa Rica: Programa Estado de la Nación (PEN).

Rojas, Pablo. 2015. «Fiscal admite error con prueba del juicio de Jairo Mora pero quiere lavarse las manos». CRhoy.com, 28 de enero de 2015. http://www.crhoy.com/archivo/fiscal-admite-error-con-prueba-del-juiciode-jairo-mora- pero-quiere-lavarse-las-manos/.

Sancho, Manuel. 2013. «OIJ de Limón detuvo a último sospechoso en asesinato de ambientalista». CRhoy.com, 10 de agosto de 2013. http://www.crhoy.com/archivo/oij- de-limon-detuvo-a-ultimo-sospechosoen-asesinato-de-ambientalista/.

Semanario Universidad. 2013. "Asesinato de Jairo Mora llena de dolor e indignación al país». Semanario Universidad, 1 de junio de 2013.

http://semanariouniversidad.ucr.cr/sin-categoria/asesinato-de-jairo-morallena-de- dolor-e-indignacin-al-pas/.

Sevilla, Álvaro. 2014. «Espacio público y protesta ciudadana. Reflexiones sobre la espacialidad del 15M». En Madrid. Materia de debate. Madrid: Club de Debates Urbanos.

Slack, Keith. 2011. «Derechos humanos e industrias extractivas en América Latina». Aportes DPLF. Revista de la Fundación para el Debido Proceso 4 (15): 4-7.

Soto, Jimena. 2013. «Diputados responsabilizan al Ejecutivo de asesinato de Jairo Mora; ecologistas y legisladores piden renuncia de Alfio Piva». CRhoy.com, 4 de junio de 2013. http://www.crhoy.com/archivo/diputados-responsabilizan-al-ejecutivo-deasesinato-de-jairo-mora-y-piden-renuncia-de-alfio-piva/. 